Tema: Soldagem

\title{
AVALIAÇÃO DA SOLDABILIDADE DO AÇO NAVAL EH36 TMCP SOLDADO POR ARCO SUBMERSO COM ELEVADO APORTE DE CALOR*
}

\author{
Tadeu Messias Donizete Borba' \\ Wagner Duarte Flores ${ }^{2}$ \\ Leonardo de Oliveira Turani ${ }^{3}$ \\ Ronaldo Cardoso Junior ${ }^{4}$
}

\begin{abstract}
Resumo
A soldagem com elevado aporte térmico é uma das alternativas adotadas pelos estaleiros para aumento da produtividade nas operações de união de materiais. No entanto, os ciclos térmicos gerados durante a soldagem podem provocar transformações microestruturais prejudiciais à tenacidade na zona afetada pelo calor (ZAC). Este estudo teve como principal propósito realizar a caracterização microestrutural e avaliar as propriedades mecânicas da ZAC do aço naval Sincron EH36 produzido na Usiminas por laminação controlada seguida de resfriamento acelerado em comparação com um aço de mesma classe de limite de escoamento produzido convencionalmente, ambos soldados pelo processo ao arco submerso em dois níveis de aporte térmico: 76 e $130 \mathrm{~kJ} / \mathrm{cm}$. Foi observado que a presença de uma microestrutura mais refinada nas diferentes regiões da ZAC, associadas ao menor tamanho de grão do metal base e ao menor carbono equivalente, foram os principais fatores que contribuíram para a excelente tenacidade da ZAC do aço Sincron em comparação ao aço convencional. Os resultados obtidos mostraram que é possível obter juntas soldadas com excelentes propriedades mecânicas ao se empregar aço Sincron para a soldagem com altos aportes de calor, e sua utilização pode ser uma estratégia para otimização dos tempos e custos de fabricação na indústria naval.
\end{abstract}

Palavras-chave: Soldagem; Aços TMCP; Resfriamento acelerado; Elevado aporte térmico.

\section{ASSESSMENT OF THE TMCP SHIPBUILDING EH36 STEEL WELDABILITY OF HIGH HEAT INPUT SUBMERGED ARC WELDING JOINT}

\begin{abstract}
The welding with high heat input is one of the main strategies used by shipyards to increase their production. However, the thermal cycles due the welding process may affect the microstructure features and the toughness in the heat affected zone (HAZ). The aim of this study was evaluate the microstructure and the mechanical properties of the HAZ of the Usiminas steel Sincron EH36 produced by controlled rolling and accelerated cooling compared to a conventional steel of the same yield strength grade, both welded with submerged-arc welding with two heat inputs: 76 to $130 \mathrm{~kJ} / \mathrm{cm}$. It was observed that the presence of a more refined microstructure in the different regions of the HAZ, associated with a smaller base metal grain size and lower carbon equivalent value, were the main factors that contributed to the excellent toughness of the HAZ Sincron steel compared to conventional steel. The results of this study showed that it is possible to obtain welded joints with excellent mechanical properties by employing Sincron steel with high heat input welding, and its use may be a strategy to optimize the time and cost of production in the shipbuilding industry.
\end{abstract}

Keywords: Welding; TMCP Steels; Accelerated cooling; High heat input welding.

\footnotetext{
Engenheiro Metalurgista, Pesquisador Centro de Tecnologia Usiminas, Ipatinga, MG, Brasil. Engenheiro Metalurgista, Pesquisador Centro de Tecnologia Usiminas, Ipatinga, MG, Brasil. Engenheiro Metalurgista, Especialista de Produto da Gerência de Atendimento ao cliente, Garantia da qualidade e Produto, Usiminas, Belo Horizonte, MG, Brasil.

4 Engenheiro Químico, Coordenador do Process Center, ESAB, Belo Horizonte, MG, Brasil.
}

* Contribuição técnica ao 69 Congresso Anual da ABM - Internacional e ao 14ํㅡㄹ ENEMET - Encontro Nacional de Estudantes de Engenharia Metalúrgica, de Materiais e de Minas, 21 a 25 de julho de 2014, São Paulo, SP, Brasil. 


\section{INTRODUÇÃO}

Nas últimas décadas, a indústria naval mundial tem passado por um processo de modernização dos seus meios de produção, objetivando a otimização dos custos e tempos de produção e a redução do peso das embarcações. Isso se deve à demanda crescente do transporte marítimo de commodities, reflexo do aumento da população e da economia mundial, e da necessidade de embarcações mais seguras, com foco na redução dos acidentes ambientais e nas emissões atmosféricas [1].

Os países asiáticos destacam-se na liderança mundial, sendo considerados os maiores fabricantes de navios de grande porte [2]. Essa hegemonia se deve principalmente à utilização de projetos inovadores de construção naval que, em grande parte, foram possíveis devido ao emprego de aços do tipo Thermo Mechanical Control Process (TMCP), pioneiramente desenvolvidos pelas siderúrgicas japonesas na década de 1970 [2,8]. Tais aços permitiram o aperfeiçoamento dos processos de união, dispensando a necessidade de preaquecimento na soldagem com baixo aporte térmico, e a possibilidade de uma maior exploração da soldagem com alto aporte térmico, resultando em um aumento da eficiência das etapas de soldagem durante a fabricação dos navios.

Na literatura é possível encontrar trabalhos $[2,3,8]$ de P\&D e de aplicação prática que comprovam a superioridade, principalmente em termos de soldabilidade, dos aços TMCP em relação aos aços convencionais. Atualmente, a Usiminas é a única siderúrgica nacional capacitada a produzir aços TMCP, denominados de aços Sincron. Recentemente, foram homologados pelas principais sociedades classificadoras internacionais do setor naval e offshore, os aços das classes de 32 , 36 e $40 \mathrm{kgf} / \mathrm{mm}^{2}$ de limite de escoamento com exigência de tenacidade a $-40^{\circ} \mathrm{C}$, até $50 \mathrm{~mm}$ de espessura. Porém, no Brasil, quase não existem trabalhos que divulguem as vantagens da aplicação desses aços na construção naval. Nesse contexto, a Usiminas iniciou estudos em conjunto com estaleiros nacionais e com os principais fabricantes de consumíveis de soldagem para o desenvolvimento da engenharia de aplicação e divulgação dos novos aços da linha Sincron. Esse trabalho é um desses estudos e tem como objetivo avaliar a soldabilidade do aço Sincron EH36 quando soldado com elevados aportes de calor, em comparação com o aço de mesma classe de limite de escoamento produzido convencionalmente.

\section{MATERIAL E MÉTODOS}

\subsection{Materiais}

Foi avaliado o aço estrutural da classe de $36 \mathrm{Kgf} / \mathrm{mm}^{2}$ de limite de escoamento, de $25 \mathrm{~mm}$ de espessura, obtido por dois métodos de processamento: (i) Aço Convencional (AC): Material processado por laminação convencional e resfriamento ao ar; (ii) EH36 Sincron (AS): Material processado por laminação controlada seguida de resfriamento acelerado. As chapas foram produzidas em escala industrial, na linha de Laminação de Chapas Grossas da Usiminas-Ipatinga. A composição química das mesmas pode ser observada na Tabela 1.

\footnotetext{
* Contribuição técnica ao 69 Congresso Anual da ABM - Internacional e ao 14ํㅡㄹ ENEMET - Encontro Nacional de Estudantes de Engenharia Metalúrgica, de Materiais e de Minas, 21 a 25 de julho de 2014, São Paulo, SP, Brasil.
} 
Tabela 1. Composição química dos aços (\% p/p)

\begin{tabular}{c|c|c|c|c|c|c|c|c|c}
\hline Aço & $\mathrm{C}$ & $\mathrm{Mn}$ & $\mathrm{Si}$ & $\mathrm{P}$ & $\mathrm{S}$ & $\mathrm{Ti}$ & $\mathrm{N}$ & $\begin{array}{c}\mathrm{Nb}+\mathrm{V}+\mathrm{N} \\
\mathrm{i}\end{array}$ & $\mathrm{Ceq}^{\mathrm{a}}$ \\
\hline $\mathrm{AC}$ & 0,16 & 1,42 & 0,18 & 0,020 & 0,002 & 0,002 & 0,0048 & 0,081 & 0,41 \\
\hline AS & 0,08 & 1,53 & 0,20 & 0,018 & 0,001 & 0,014 & 0,0036 & 0,024 & 0,34 \\
\hline
\end{tabular}

\subsection{Confecção e Caracterização das Juntas Soldadas}

Para cada material, foram soldadas juntas através do processo de soldagem ao arco submerso (SAW) Tandem Arc utilizando-se os aportes térmicos de 76 e $130 \mathrm{~kJ} / \mathrm{cm}$. A direção de soldagem foi transversal à direção de laminação. Utilizou-se como consumíveis a combinação arame-fluxo da classe AWS A5.17 F7A4-EM12K, sendo o fluxo do tipo aglomerado neutro e básico, empregado comumente na construção naval. Detalhes dos parâmetros de soldagem e da configuração do chanfro encontram-se na Tabela 2.

Após a soldagem, realizou-se análise metalográfica de seção transversal à solda, em amostras atacadas com reativo nital $4 \%$. Os constituintes microestruturais do metal de solda (MS) e da região de grãos grosseiros da ZAC (GGZAC) foram identificados de acordo com a nomenclatura adotada pelo TWI The Welding Institut [4], Tabela 3. A distribuição do tamanho do grão austenítico prévio (TGY) na GGZAC, foi determinada através da realização de 33 medições da maior distância entre as ferritas próeutetoides, formadas no contorno de grão da austenita prévia, próximo a linha de fusão (LF). Nessa mesma seção, foi realizado ensaio de dureza Vickers com carga de $3 \mathrm{kgf}$ e distância entre impressões de $0,5 \mathrm{~mm}$ no metal base (MB) e no MS e ao longo de toda a extensão da ZAC. A representação esquemática destas medições pode ser vista na Figura 1.

Os ensaios de impacto Charpy- $V$ foram realizados em corpos de prova (cps) confeccionados de acordo com a norma ASTM A370 [6]. Os cps foram retirados a $1 / 4$ e a $1 / 2$ da espessura para avaliação do $M S$, e a $1 / 4$ da espessura para análise das regiões da linha de fusão (LF), LF $+2 \mathrm{~mm}, L F+5 \mathrm{~mm}$ e $L F+20 \mathrm{~mm}$, Figura 2. A temperatura do ensaio foi de $-40^{\circ} \mathrm{C}$, que é a mesma especificada para o metal base. Para cada junta soldada foram retirados transversalmente ao cordão de solda $2 \mathrm{cps}$ para o ensaio de tração, confeccionados de acordo com o código ASME, Section IX [7], e ensaiados com base na norma ASTM A370 [6].

A observação das superfícies de fratura dos cps de Charpy foi conduzida em microscópio eletrônico de varredura (MEV). As análises foram realizadas nos $\mathrm{cps}$ com entalhe posicionado na LF.

Tabela 2. Parâmetros de soldagem utilizados e configuração do chanfro (valores nominais).

\begin{tabular}{|c|c|c|c|c|c|}
\hline $\begin{array}{l}\text { Aporte Térmico } \\
(\mathrm{kJ} / \mathrm{cm})\end{array}$ & $\begin{array}{l}\text { Corrente } \\
\text { (A) }\end{array}$ & $\begin{array}{c}\text { Tensão } \\
\text { (V) }\end{array}$ & $\begin{array}{l}\text { Velocidade } \\
\text { (cm/min) }\end{array}$ & $\begin{array}{l}\mathrm{N}^{\circ} \text { de } \\
\text { passes }\end{array}$ & Geometria do Chanfro \\
\hline \multirow{2}{*}{76} & $1100^{a}$ & $38^{a}$ & \multirow{2}{*}{60} & \multirow{2}{*}{2} & \multirow{3}{*}{$30 \%$} \\
\hline & $1000^{b}$ & $35^{b}$ & & & \\
\hline \multirow{2}{*}{130} & $1100^{a}$ & $38^{a}$ & \multirow{2}{*}{35} & \multirow{2}{*}{1} & \\
\hline & $1000^{b}$ & $35^{b}$ & & & $12 \mathrm{~mm}$ \\
\hline
\end{tabular}

Obs.: $a-1^{\circ}$ Eletrodo, fonte do tipo corrente contínua; $b-2^{\circ}$ Eletrodo, fonte do tipo corrente alternada.

* Contribuição técnica ao 69을 Congresso Anual da ABM - Internacional e ao 14ํㅡㄹ ENEMET - Encontro Nacional de Estudantes de Engenharia Metalúrgica, de Materiais e de Minas, 21 a 25 de julho de 2014, São Paulo, SP, Brasil. 


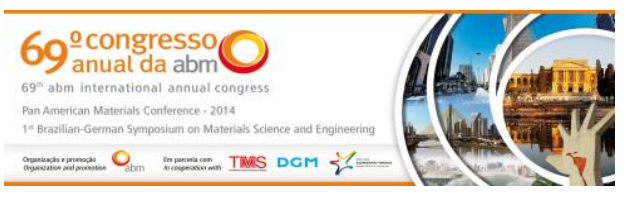

Tabela 3. Constituintes microestruturais do MS e da ZAC segundo $\mathrm{TWI}^{(4)}$

\begin{tabular}{|c|c|}
\hline Metal de Solda & Zona Afetada pelo Calor \\
\hline $\mathrm{FS}(\mathrm{A})=$ Ferrita com segunda fase alinhada & $\mathrm{ACA}=$ Ferrita com segunda fase alinhada \\
\hline $\mathrm{PF}(\mathrm{I})=$ Ferrita intragranular poligonal & $\begin{array}{c}\text { ACN }=\text { Ferrita com segunda fase não } \\
\text { alinhada }\end{array}$ \\
\hline $\mathrm{AF}=$ Ferrita acicular & FN = Ferrita de Widmanstätten intragranular \\
\hline \multicolumn{2}{|c|}{$\mathrm{PF}(\mathrm{G})=$ Ferrita de contorno de grão } \\
\hline \multicolumn{2}{|c|}{$\mathrm{FC}=$ Agregado ferrita-carboneto } \\
\hline \multicolumn{2}{|c|}{$\mathrm{P}=$ Perlita } \\
\hline \multicolumn{2}{|c|}{ Outros $=\mathrm{P}+\mathrm{FC}$} \\
\hline
\end{tabular}

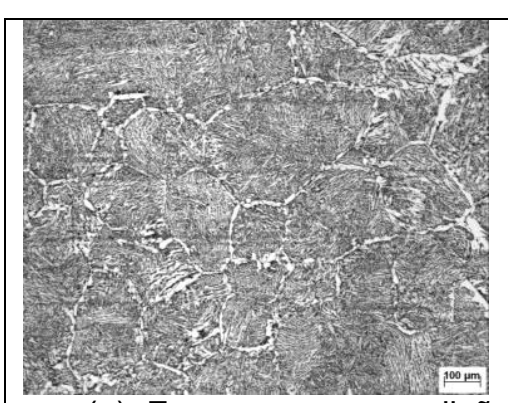

(a) Esquema para medição do TGy na GGZAC

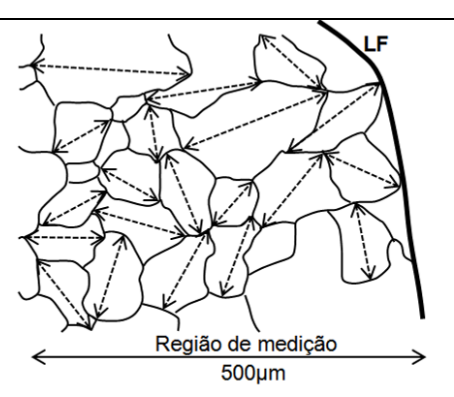

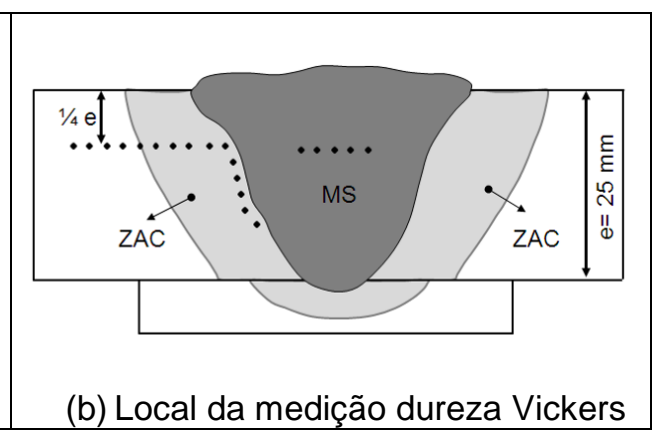

(b) Local da medição dureza Vickers

Figura 1. Representação esquemática das regiões em que foram realizadas as medições do TGY e de dureza Vickers.

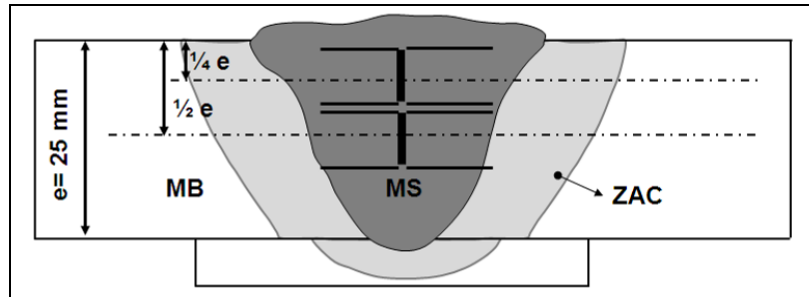

a) Entalhe no metal de solda.

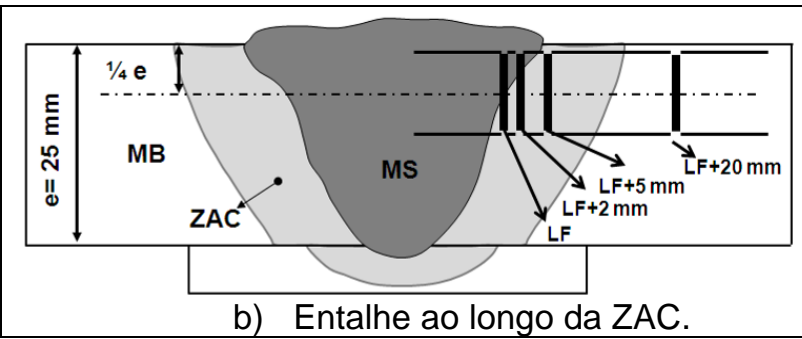

b) Entalhe ao longo da ZAC.

Figura 2 - Representação esquemática da posição dos entalhes nos cps para ensaio Charpy.

\section{RESULTADOS E DISCUSSÃO}

\subsection{Microestrutura do Metal Base}

As microestruturas características dos aços AC e AS podem ser observadas na Figura 3. Foi observado que o aço AC apresentou um bandeamento microestrutural de ferrita poligonal e perlita. Já para o aço AS, percebe-se uma microestrutura homogênea ao longo da espessura, e a presença, em maior quantidade, de bainita e, em menor quantidade, de ferrita poligonal e perlita, bem mais refinadas do que os constituintes observados no aço AC, em função do processo TMCP empregado no aço AS.

* Contribuição técnica ao $69^{\circ}$ Congresso Anual da ABM - Internacional e ao 14ํㅡㄹ ENEMET - Encontro Nacional de Estudantes de Engenharia Metalúrgica, de Materiais e de Minas, 21 a 25 de julho de 2014, São Paulo, SP, Brasil. 


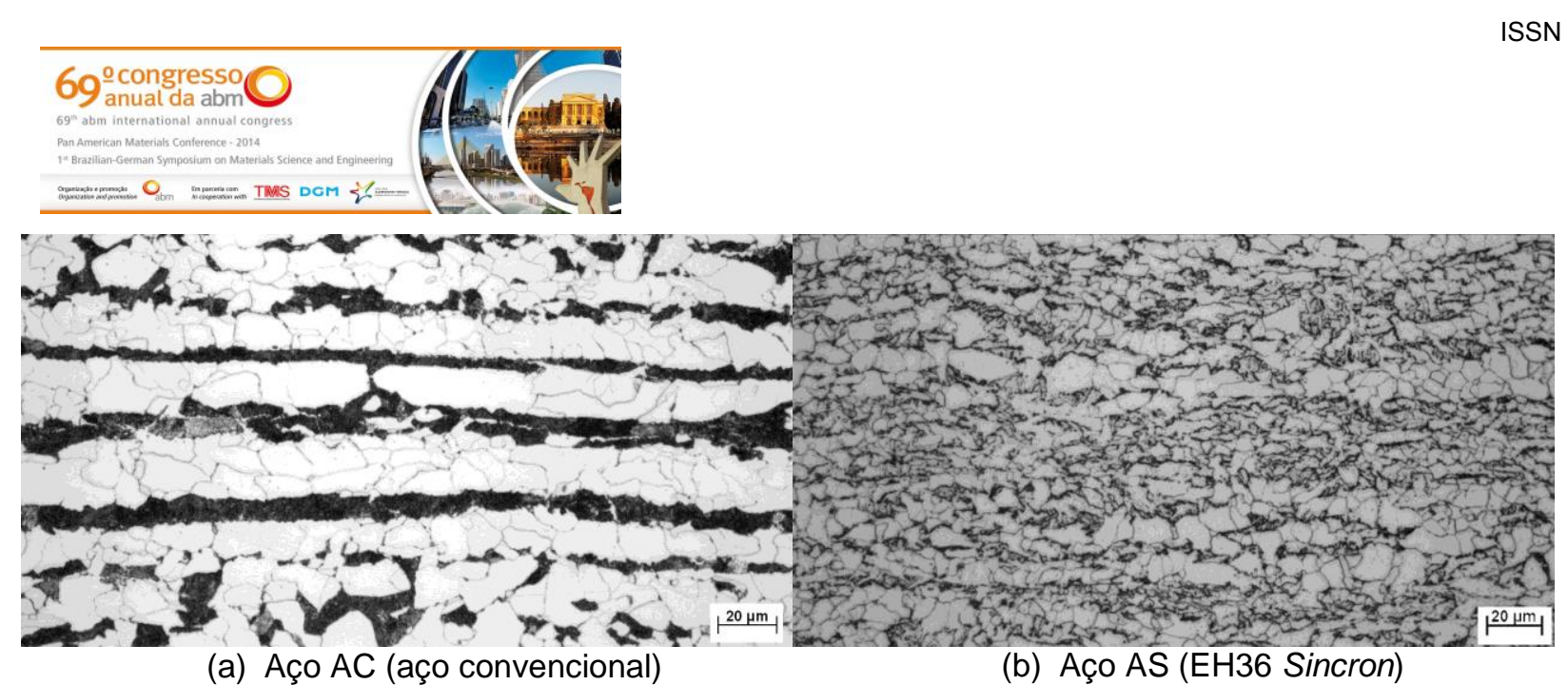

(a) Aço AC (aço convencional)

(b) Aço AS (EH36 Sincron)

Figura 3. Microestrutura do metal base. Ataque nital 4\%. Aumento original: 500X.

\subsection{Avaliação das Juntas Soldadas}

\subsubsection{Microestrutura do metal de solda}

As microestruturas típicas do MS para o aço estudado e o resultado da fração volumétrica de cada constituinte são mostradas nas Figuras 4 e 5, respectivamente. De forma geral, independentemente do aço, percebe-se que o aumento do aporte térmico proporcionou um aumento na proporção de $P F(G)$ e $P F(I)$, que se formaram da decomposição da austenita em elevadas temperaturas de transformação favorecidas pelas baixas velocidades de resfriamento dos processos de soldagem com alto aporte térmico. $\mathrm{O}$ aço $\mathrm{AC}$ apresentou maior quantidade de perlita, formada preferencialmente junto à $P F(G)$, sendo que a sua fração aumentou com o aumento do aporte térmico, Figura 5.

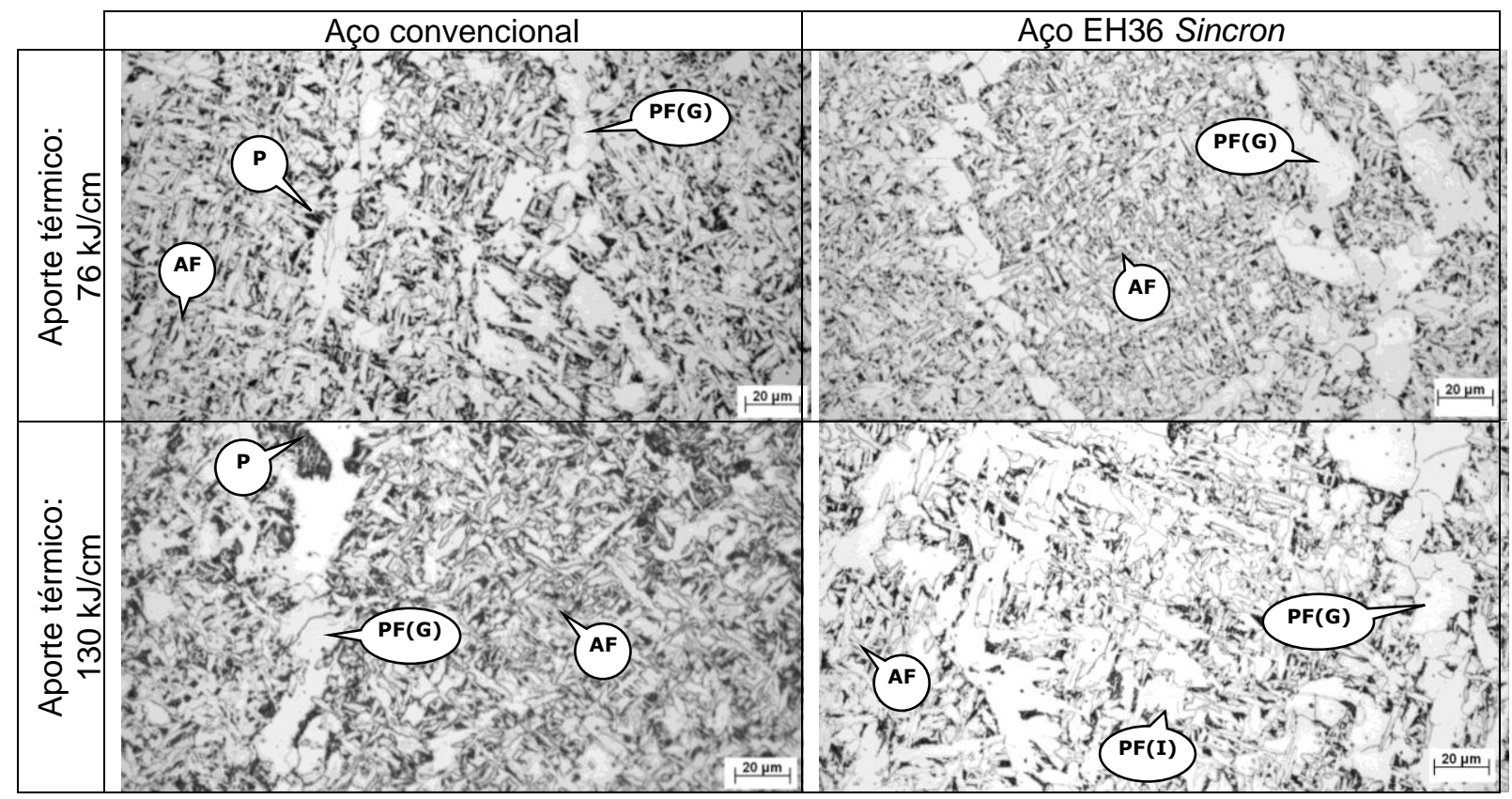

Figura 4. Microestrtura do MS. Ataque nital 4\%. Aumento original: 500X.

* Contribuição técnica ao $69^{\circ}$ Congresso Anual da ABM - Internacional e ao 14ํㅡㄹ ENEMET - Encontro Nacional de Estudantes de Engenharia Metalúrgica, de Materiais e de Minas, 21 a 25 de julho de 2014, São Paulo, SP, Brasil. 

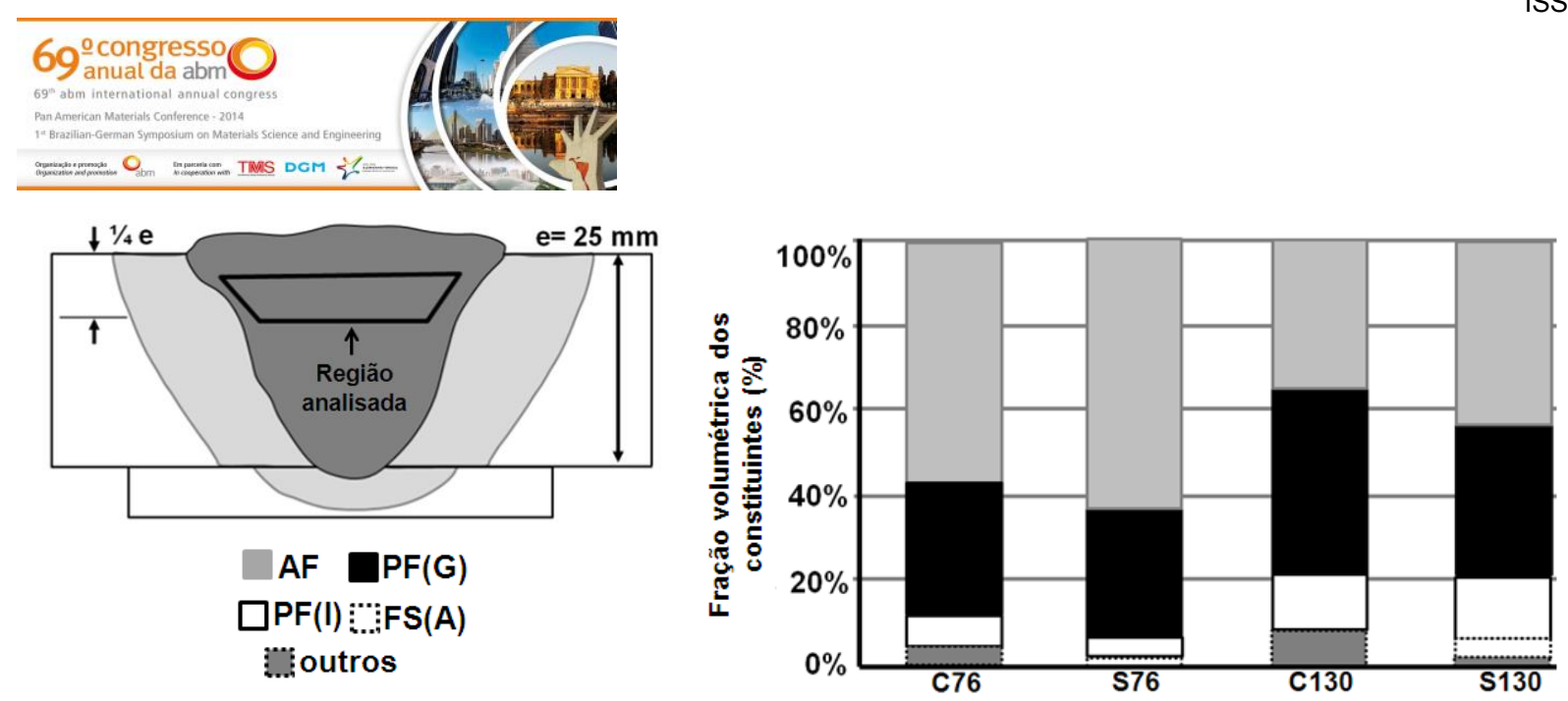

Figura 5. Fração volumétrica dos constituintes no $M S$. $C 76=$ junta do aço $A C$ soldado com $76 \mathrm{~kJ} / \mathrm{cm}$; C130 = junta do aço AC soldado com $130 \mathrm{~kJ} / \mathrm{cm} ; \mathrm{S} 76$ = junta do aço AS soldado com $76 \mathrm{~kJ} / \mathrm{cm}$; $\mathrm{S} 130$ = junta do aço AS soldado com $130 \mathrm{~kJ} / \mathrm{cm}$.

\subsubsection{Microestrutura da ZAC}

Quando aplicado aporte térmico de $76 \mathrm{~kJ} / \mathrm{cm}$ observou-se que o TGy, próximo à LF, para as juntas soldadas dos aços AS (S76) e AC (C76), variou entre 50-100 $\mu \mathrm{m}$ e 100-200 $\mu \mathrm{m}$, respectivamente. Com o aumento do aporte térmico houve um aumento do TGy, sendo que para o aço AS (S130) ficaram entre 100-250 $\mu \mathrm{m}$ e para os aços AC (C130) entre 200-300 $\mu \mathrm{m}$, conforme observado na Figura 6. O menor TGy para os aços AS pode estar associado, principalmente, à presença de precipitados de $\mathrm{Ti}$ homogeneamente distribuídos no $\mathrm{MB}$, que dificultaram $\mathrm{o}$ crescimento de grão da austenita durante a soldagem [2,3,12].

Avaliação microestrutural da GGZAC pode ser observada na Figura 7. As juntas soldadas do aço AC revelaram a presença dos seguintes constituintes microestruturais: $P F(G)$ e $P$ nos contornos de grãos da austenita prévia, e $F N, F C$, ACA e ACN no interior dos grãos. Para as juntas do aço AS, foram observados os mesmos constituintes presentes nas juntas do aço AC, porém bem mais refinados.

$\mathrm{O}$ aumento do aporte térmico de 76 para $130 \mathrm{~kJ} / \mathrm{cm}$ favoreceu a formação de constituintes mais grosseiros e de mais altas temperaturas de transformação, principalmente os constituintes $\mathrm{PF}(\mathrm{G})$ e ACA.

A Figura 8 mostra a seção transversal da ZAC para os aços estudados. Observa-se que a microestrutura apresenta-se mais grosseira próxima à LF e que a GGZAC do aço AC é mais extensa do que a do aço AS.



Figura 6. Distribuição de frequência para o tamanho de grão da austenita prévia (TGY).

* Contribuição técnica ao 69ำ Congresso Anual da ABM - Internacional e ao $14^{\circ}$ ENEMET - Encontro Nacional de Estudantes de Engenharia Metalúrgica, de Materiais e de Minas, 21 a 25 de julho de 2014, São Paulo, SP, Brasil. 

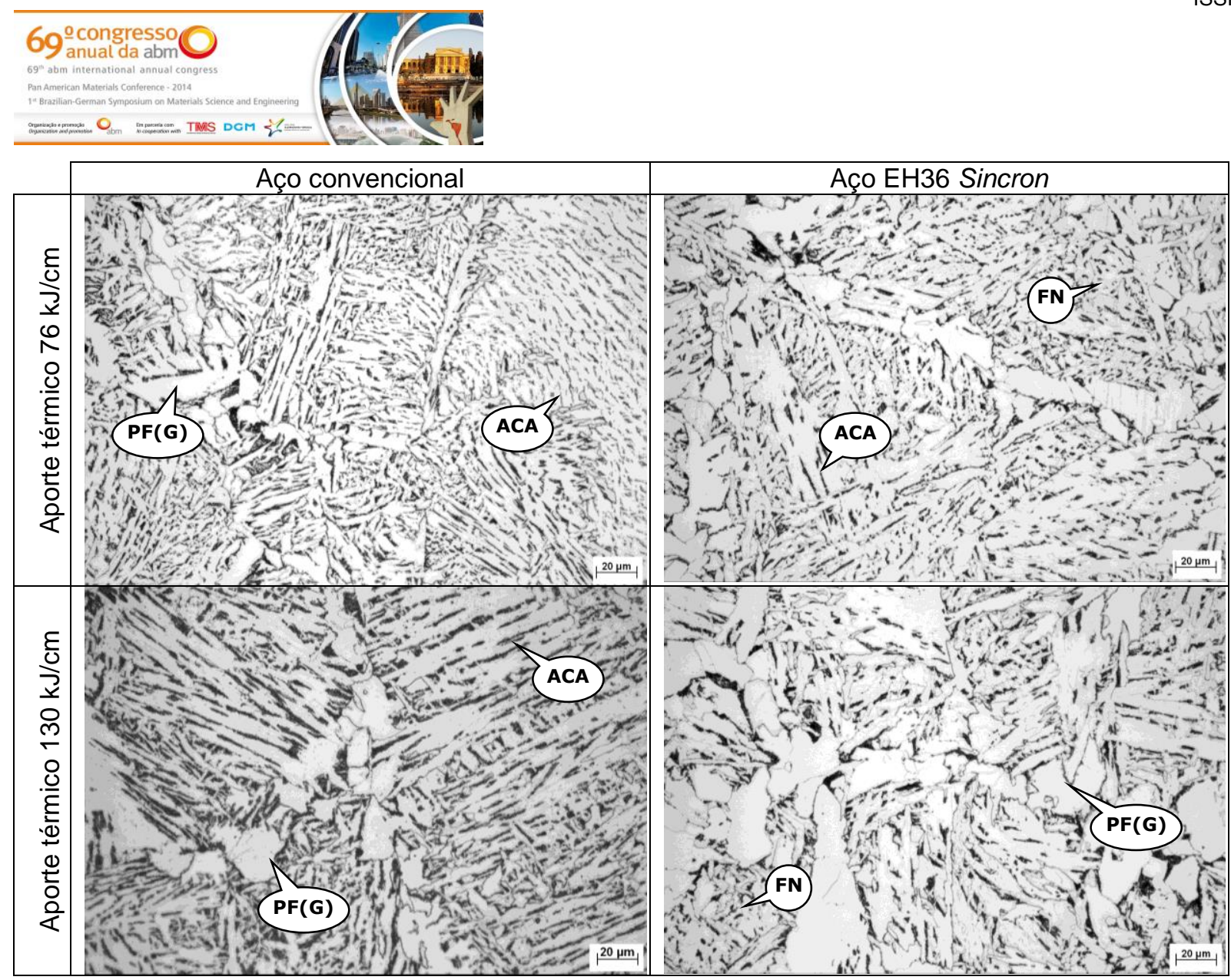

Figura 7. Microestrutura na região GGZAC. Ataque nital 4\%. Aumento original: 500X.

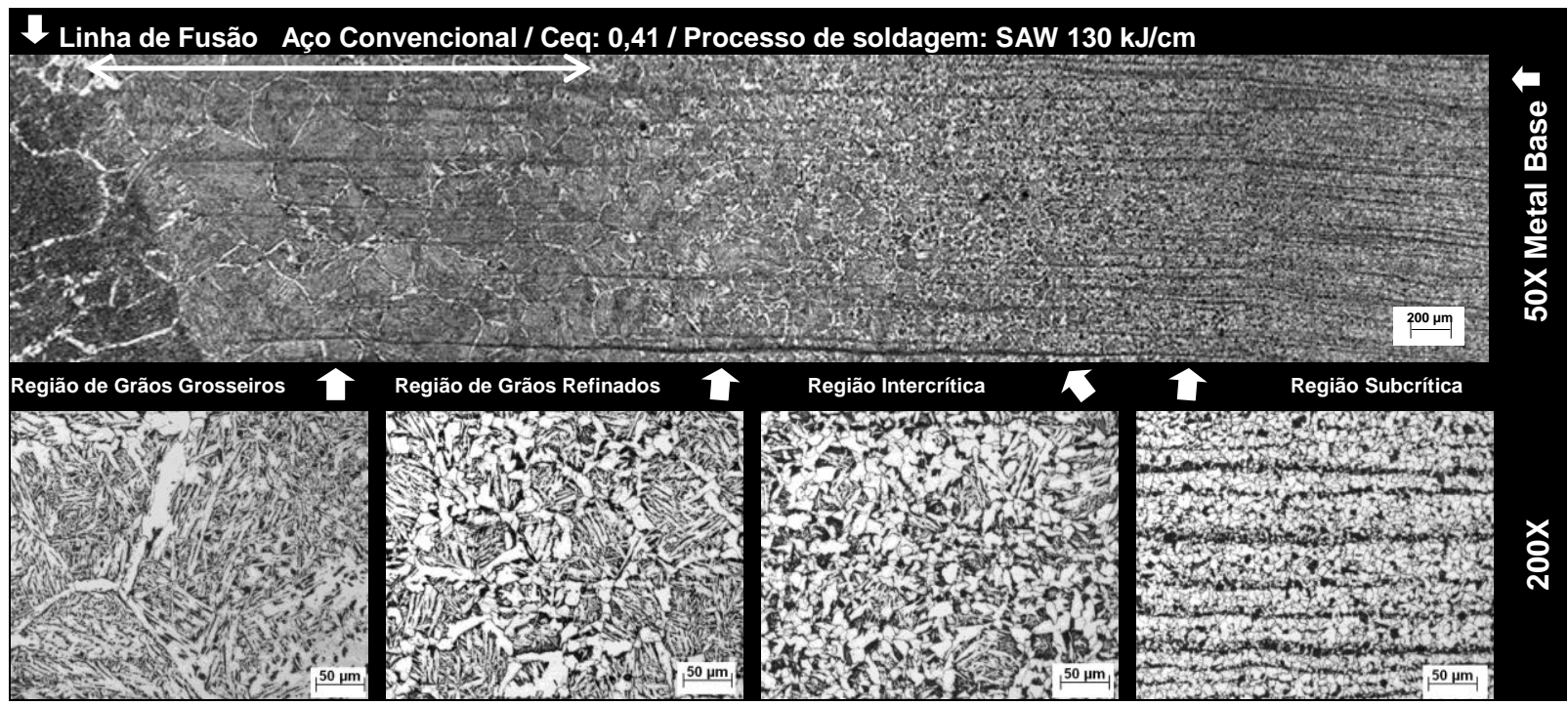

(a) Aço convencional.

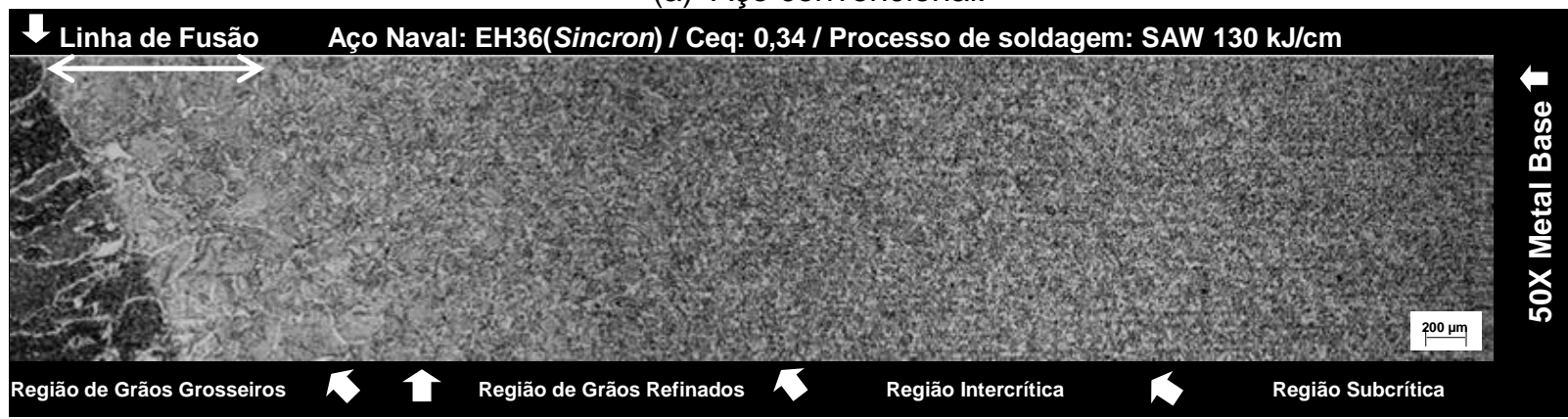

* Contribuição técnica ao $69^{\circ}$ Congresso Anual da ABM - Internacional e ao 14ํㅡㄹ ENEMET - Encontro Nacional de Estudantes de Engenharia Metalúrgica, de Materiais e de Minas, 21 a 25 de julho de 2014, São Paulo, SP, Brasil. 

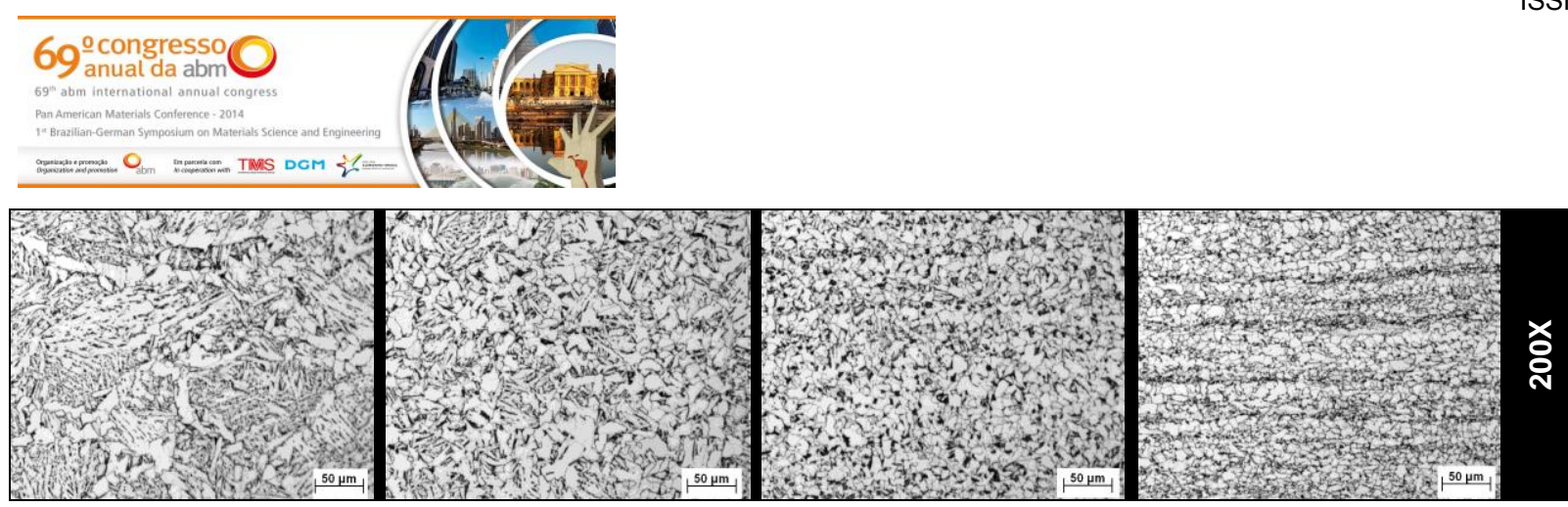

(b) Aço EH36 Sincron.

Figura 8. Seção transversal ao cordão de solda das juntas soldadas com $130 \mathrm{~kJ} / \mathrm{cm}$. Ataque nital $4 \%$.

\subsubsection{Ensaio de dureza}

O perfil de dureza ao longo da ZAC e GGZAC são apresentados na Figura 9.

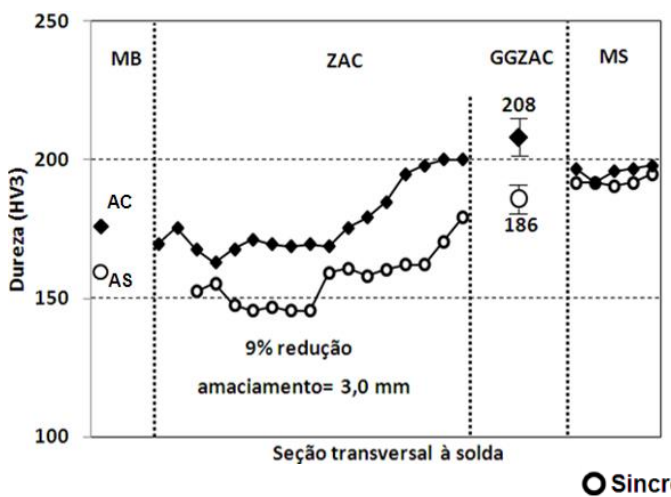

(a) Aporte térmico $76 \mathrm{~kJ} / \mathrm{cm}$

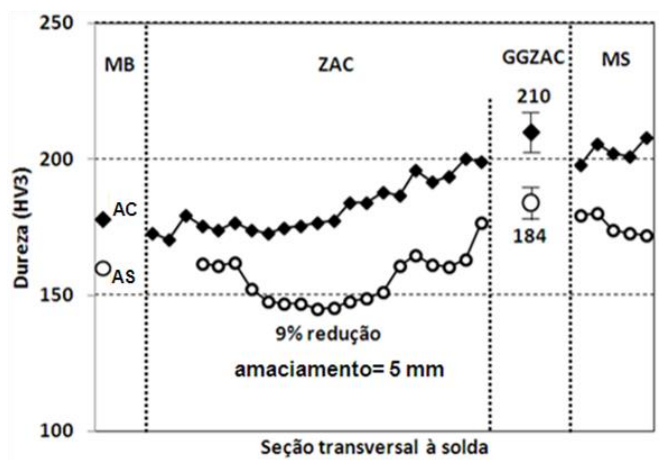

(b) Aporte térmico $130 \mathrm{~kJ} / \mathrm{cm}$

Figura 9. Perfil de dureza Vickers, em seção transversal ao cordão de solda. Carga de 3 kgf.

Nota-se que as juntas $A S(C=0,08 \%$, Ceq $=0,34)$ apresentaram menores valores de dureza em comparação às juntas $A C(C=0,16 \%$, Ceq $=0,41)$, justificados pelo seu menor teor de carbono e menor valor de carbono equivalente. Foi verificado, para todas as amostras soldadas do aço AS, o amaciamento da ZAC. A maior largura da zona amaciada, $5 \mathrm{~mm}$, foi observada para as juntas soldadas com $130 \mathrm{~kJ} / \mathrm{cm}$, que teve uma redução de $9 \%$ da dureza na ZAC em relação ao valor do MB. Já para o aço AC esse efeito é menos significativo devido ao seu maior carbono equivalente e maior crescimento de grão, o que the confere uma maior temperabilidade. Em contrapartida, a presença de constituintes grosseiros e de elevada resistência mecânica, resulta em significativa queda de tenacidade dos aços AC. No caso dos aços TMCP, parte da resistência mecânica é obtida através de transformações microestruturais e endurecimento por aumento da densidade de discordâncias, que ocorrem durante o processamento termomecânico e o resfriamento acelerado. Dessa forma, quando os aços AS são submetidos a ciclo térmicos de soldagem que proporcionam baixas velocidades de resfriamento, como o caso de soldagem com alto aporte térmico, há a redução da resistência mecânica em uma pequena faixa da ZAC. Essa parcela não pode ser totalmente restaurada devido ao baixo carbono equivalente deste aço, o que impossibilita a formação de microestruturas de maior resistência mecânica [11].

\subsubsection{Propriedades em tração}

Os resultados obtidos nos ensaios de tração podem ser observados na Tabela 4. 0 único requisito especificado para as juntas soldadas, segundo as normas navais para qualificação de procedimento de soldagem, é que o limite de resistência (LR) seja superior aos valores especificados para o MB. Sendo assim, todas as juntas

* Contribuição técnica ao $69^{\circ}$ Congresso Anual da ABM - Internacional e ao 14ํㅡㄹ ENEMET - Encontro Nacional de Estudantes de Engenharia Metalúrgica, de Materiais e de Minas, 21 a 25 de julho de 2014, São Paulo, SP, Brasil. 


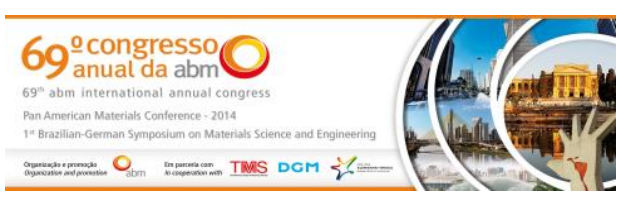

podem ser consideradas aprovadas, já que o LR das juntas foram superiores a $490 \mathrm{MPa}$. O aumento do aporte térmico não afetou as propriedades das juntas soldadas do aço AC. Porém, no caso das juntas soldadas do aço AS, observa-se uma pequena redução no LR. Os menores valores de LR das juntas soldadas do aço AS podem estar associados à ocorrência preferencial da fratura na região amaciada da ZAC. No entanto, segundo a literatura [2,10,11], para que o amaciamento da ZAC exerça um efeito deletério significativo sobre o desempenho das juntas soldadas a sua extensão deve exceder $25 \%$ da espessura da chapa, 0 que não foi o caso para os materiais avaliados, Figura 9. Na literatura [2,10,11] também é possível encontrar trabalhos que comprovam que o amaciamento da ZAC não afeta a vida em fadiga de juntas soldadas de aços TMCP, pois o comportamento em fadiga é principalmente afetado pelo fator de concentração de tensão na junta, ou seja, pela forma do reforço do cordão de solda, e não pelas propriedades estáticas em tração do material.

Tabela 4. Resultados obtidos nos ensaios de tração das juntas soldadas.

\begin{tabular}{|c|c|c|c|c|}
\hline Metal Base & \multicolumn{3}{|c|}{ Limite de Resistência (MPa) } & \multirow{4}{*}{ Local da fratura } \\
\hline $\mathrm{AC}$ & & 602 & & \\
\hline AS & \multicolumn{3}{|c|}{559} & \\
\hline Junta soldada & CP1 & CP2 & Média & \\
\hline C76 & 601 & 598 & 600 & \multirow{4}{*}{ ZAC } \\
\hline S76 & 552 & 549 & 550 & \\
\hline C130 & 604 & 602 & 603 & \\
\hline $\mathrm{S} 130$ & 526 & 537 & 531 & \\
\hline \multicolumn{5}{|c|}{ Limite de resistência para aço naval EH36: 490 - $620 \mathrm{MPa}$} \\
\hline
\end{tabular}

\subsubsection{Ensaio de impacto charpy do metal de solda}

Os valores médios de energia absorvida em ensaio Charpy-V para os corpos de prova retirados do MS a $1 / 4$ e $1 / 2$ da espessura estão apresentados na Figura 10. Os melhores resultados foram obtidos para as juntas do aço AS em especial para os corpos de prova retirados a $1 / 2$ da espessura das juntas soldadas com aporte térmico de $76 \mathrm{~kJ} / \mathrm{cm}$. Essas juntas foram obtidas com deposição de dois passes de solda, de forma que os corpos de prova com entalhe posicionado a $1 / 2$ da espessura amostraram grande parte da região reaquecida pelo passe subsequente. Sob tais circunstâncias, a microestrutura nessa região exibiu maior refinamento microestrutural, o que é benéfico para tenacidade. Os menores valores de energia absorvida foram observados nas juntas soldadas dos aços AC, podem ser atribuídos à formação de microestruturas grosseiras como $P F(G)$ e $P F(I)$ em detrimento à formação de AF no MS. A propagação da trinca ao longo da $P F(G)$ no $M S$ pode ser intensificada pela presença de estrutura perlítica e constituintes do tipo M-A e ou carbonetos ao longo do contorno de grão ${ }^{(12)}$ que tiveram sua formação favorecida devido à elevada diluição do MS, decorrência dos elevados aportes utilizados, e do alto teor de $\mathrm{C}$ e de elementos de liga do aço $\mathrm{AC}$, reduzindo a tenacidade do $\mathrm{MS}$ desses aços [2]. Foi observada uma maior quantidade de perlita, adjacente à $P F(G)$, nas juntas do aço $A C$, especialmente quando soldado com $130 \mathrm{~kJ} / \mathrm{cm}$ de aporte térmico. Embora a $P F(G)$ seja um constituinte dúctil, a sua associação com constituintes de maior resistência pode provocar a concentração de deformação na mesma (região mais macia), resultando assim na nucleação de trincas e reduzindo a resistência à fratura por clivagem [5,9,12]. A Figura 10(c) mostra a propagação preferencial da fratura ao longo da $\mathrm{PF}(\mathrm{G})$ em corpos de prova Charpy retirados do MS.

* Contribuição técnica ao $69^{\circ}$ Congresso Anual da ABM - Internacional e ao 14ํㅡㄹ ENEMET - Encontro Nacional de Estudantes de Engenharia Metalúrgica, de Materiais e de Minas, 21 a 25 de julho de 2014, São Paulo, SP, Brasil. 
Vale ressaltar que os aportes de calor avaliados nesse estudo foram superiores aos recomendados para juntas soldadas que utilizam a combinação F7A4-EM12K, reforçando a necessidade da escolha adequada do consumível de soldagem não apenas em função dos requerimentos de projeto, mas também em relação ao MB e ao procedimento de soldagem aplicado.

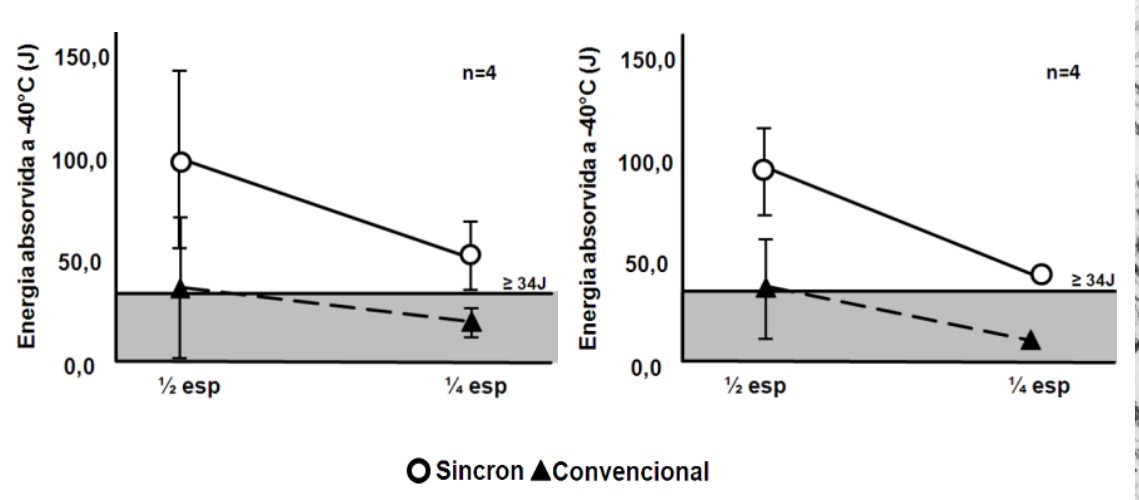

(a) Aporte térmico $76 \mathrm{~kJ} / \mathrm{cm}$

(b) Aporte térmico $130 \mathrm{~kJ} / \mathrm{cm}$

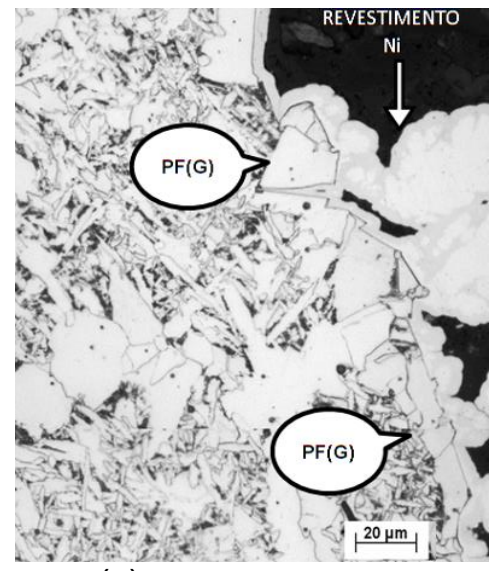

(c) Ataque Nital 4\%. Aumento original: 500X.

Figura 10. Energia absorvida durante ensaio de impacto Charpy-V em corpos de prova retirados no MS e seção transversal de corpo de prova Charpy do aço $A C(130 \mathrm{~kJ} / \mathrm{cm}) \mathrm{com}$ entalhe posicionado no MS, evidenciando a propagação da fratura na $P F(G)$.

\subsubsection{Ensaio de impacto charpy na ZAC}

A comparação entre os valores médios de energia absorvida é apresentado nos gráficos na Figura 11. Todos os valores para a ZAC das juntas do aço AS, foram superiores ao especificado para o metal base. $O$ menor valor individual, $111 \mathrm{~J}$, foi

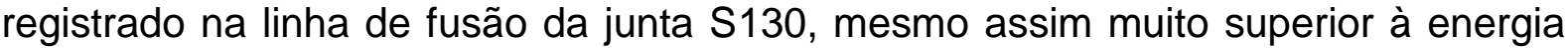
mínima especificada para o grau EH36 $\left(34 \mathrm{~J}\right.$ a $\left.-40^{\circ} \mathrm{C}\right)$. Por outro lado, observa-se que todos os resultados do aço AC foram inferiores aos do aço AS, sendo que todos os corpos de prova com entalhe posicionado na LF tiveram resultados abaixo do mínimo especificado. Para esse mesmo aço verificou-se que, para o aporte térmico de $130 \mathrm{~kJ} / \mathrm{cm}$, junta C130, além da LF os corpos de prova retirados na posição LF + $2 \mathrm{~mm}$ também ficaram abaixo do especificado.

Foi realizada análise metalográfica dos corpos de prova com entalhe na LF das juntas $\mathrm{S} 130$ que apresentaram o menor e o maior valor de energia absorvida, $111 \mathrm{~J}$ e $432 \mathrm{~J}$ respectivamente, e o pior resultado, $5 \mathrm{~J}$, da junta $\mathrm{C} 130$, com o objetivo de determinar as razões para a ocorrência das dispersões de valores de energia absorvida obtidas. Em todos esses casos, ao longo da ponta dos entalhes observouse a presença de regiões constituídas por MS, que apresentou baixos valores de energia absorvida, e por GGZAC, que é tradicionalmente considerada como região localizada de fragilização $[5,9,12]$. No caso do corpo de prova que apresentou $111 \mathrm{~J}$ de energia absorvida, o MS corresponde a $32 \%$ da extensão do entalhe, o que explica o menor valor de energia observado para esse corpo de prova em relação aos demais retirados na mesma posição. Segundo Kudoh e Pisaroki [13], a energia absorvida em corpos de prova Charpy com uma distribuição heterogênea de microestruturas ao longo do entalhe é dominada pela região de menor tenacidade quando esta ocupa mais de $30 \%$ do entalhe. No caso do corpo de prova da junta C130 que registrou valor de energia absorvida de $5 \mathrm{~J}$, houve uma grande proporção

\footnotetext{
* Contribuição técnica ao $69^{\circ}$ Congresso Anual da ABM - Internacional e ao 14ํㅡㄹ ENEMET - Encontro Nacional de Estudantes de Engenharia Metalúrgica, de Materiais e de Minas, 21 a 25 de julho de 2014, São Paulo, SP, Brasil.
} 


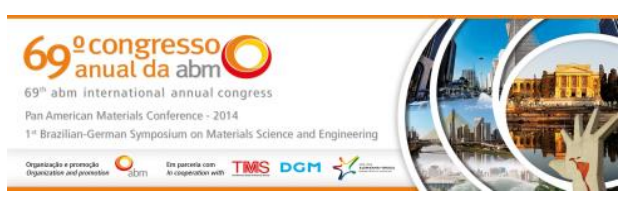

de MS, $41 \%$, sendo o restante composto pela GGZAC. No caso do corpo de prova retirado da LF da junta S130 que apresentou $432 \mathrm{~J}$, foi observado que $43 \%$ da ponta do entalhe era composta pela microestrutura refinada, típica da região de transição entre a região de grãos grosseiros e grãos refinados da ZAC, o que justifica a melhor tenacidade desse corpo de prova. Foi comprovado também que a menor extensão da GGZAC do aço AS auxiliou na obtenção de melhores resultados.

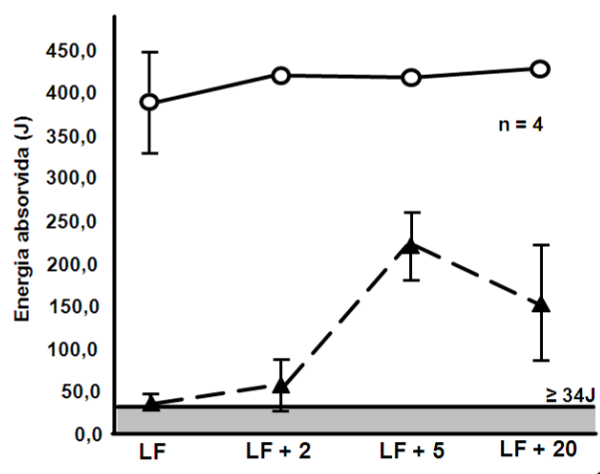

(a) Aporte térmico $76 \mathrm{~kJ} / \mathrm{cm}$

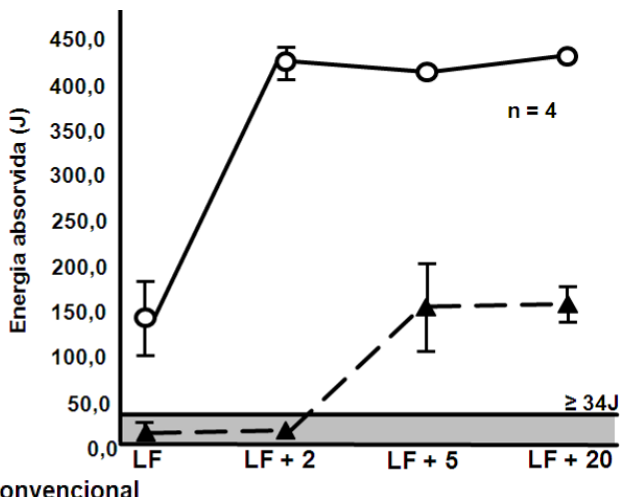

(b) Aporte térmico $130 \mathrm{~kJ} / \mathrm{cm}$

Figura 11. Energia absorvida no ensaio de impacto Charpy-V em corpos de prova retirados na ZAC.

Na Figura 12 observa-se a superfície de fratura de alguns corpos de prova. Observase que com o aumento do aporte térmico e, consequentemente, com a redução da taxa de resfriamento, há um aumento qualitativo do tamanho das facetas de clivagem. As fraturas referentes ao aço AS, quando comparados com as do aço AC soldados na mesma condição, apresentaram menores tamanhos de facetas de clivagem, o que pode estar relacionado com os menores tamanhos de grãos de austenita prévia dos aços TMCP. Segundo Alé [5] o tamanho da faceta de clivagem está relacionado ao tamanho dos pacotes, que são regiões com a mesma orientação cristalográfica formadas dentro de um mesmo grão austenítico prévio. Esses pacotes servem como barreira à propagação das trincas, determinando, uma correlação entre o tamanho das facetas e o tamanho dos pacotes. Quanto menor o TG $\mathrm{F}_{\mathrm{yp}}$, menor o tamanho dos pacotes e, portanto, menor o tamanho das facetas.

Com o aumento do aporte térmico de 76 para $130 \mathrm{~kJ} / \mathrm{cm}$, observou-se uma queda na tenacidade do aço $A C$ o que não foi observado para o aço $A S$, Figura 11. $O$ aço AC possui maiores teores de elementos de liga, o que favorece ao aumento da resistência mecânica, porém contribui para uma redução na tenacidade [2,12], o que está associado à formação de constituintes mais grosseiros, e frágeis como a ACA e a FP como observado por Alé(5). A Figura 13 mostra trincas secundárias de clivagem ocorrendo em planos ortogonais dentro de um mesmo pacote de ferrita de segunda fase alinhada. Isso é um forte indício de uma baixa resistência à clivagem do constituinte ACA. É provável também que a nucleação da fratura por clivagem na região de grãos grosseiros possa ocorrer no $M-A[5,9,12]$ dos constituintes ACA e $A C N$, que podem ser estabilizados por alguns elementos de liga como, por exemplo, o V e o C, porém não foi possível verificar tal afirmação. Silva [9] comenta que para tempos de resfriamento maiores é possível ocorrer a estabilização da austenita remanescente devido ao seu enriquecimento em carbono provocado pela ferrita que possui menor solubilidade em carbono. Devido principalmente ao maior teor de $\mathrm{C}$ do aço AC, a probabilidade de formar constituintes M-A na GGZAC é maior do que no aço AS, e sua presença pode também justificar a menor tenacidade do aço AC.

\footnotetext{
* Contribuição técnica ao $69^{\circ}$ Congresso Anual da ABM - Internacional e ao 14ํㅡㄹ ENEMET - Encontro Nacional de Estudantes de Engenharia Metalúrgica, de Materiais e de Minas, 21 a 25 de julho de 2014, São Paulo, SP, Brasil.
} 




Figura 12. Superfície de fratura de corpos de prova Charpy-V observados via MEV. Entalhe possicionado na linha de fusão. Temperatura de ensaio $-40^{\circ} \mathrm{C}$. Aumento original : $500 \mathrm{X}$.
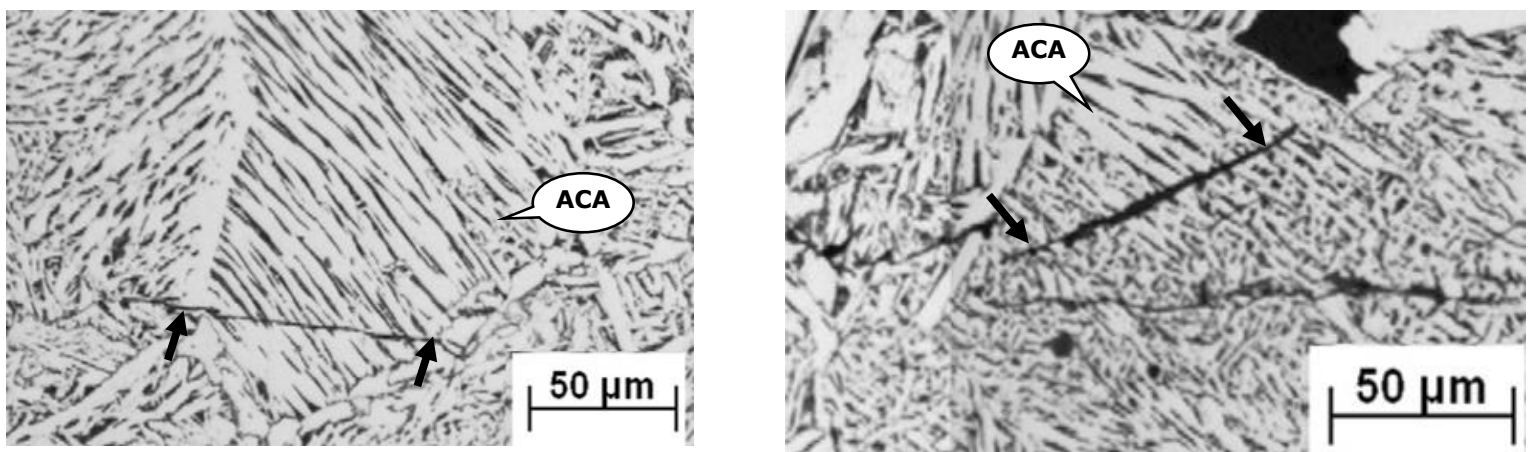

Figura 13. Seção transversal à superfície de fratura de corpo de prova Charpy com entalhe posicionado na LF da junta C76 evidenciando trincas secundárias (seta) ao longo do constituinte ACA. Ataque: Nital $4 \%$. Aumento original: 200X

\section{CONCLUSÃO}

Diante dos resultados apresentados, pode-se concluir que o aço EH36 produzido via laminação controlada seguida de resfriamento acelerado, soldado a arco submerso unilateralmente com 76 e $130 \mathrm{~kJ} / \mathrm{cm}$ de aporte térmico e empregando os consumíveis comumente utilizados na industria naval, apresenta resultados superiores de soldabilidade em relação ao aço convencional. Foi mostrado que o aço Sincron pode ser soldado com elevado aporte térmico sem deterioração de suas propriedades mecânicas, em especial da tenacidade, o que se constitui em uma excelente alternativa para aumento de produtividade dos estaleiros nacionais.

* Contribuição técnica ao $69^{\circ}$ Congresso Anual da ABM - Internacional e ao 14ํㅡㄹ ENEMET - Encontro Nacional de Estudantes de Engenharia Metalúrgica, de Materiais e de Minas, 21 a 25 de julho de 2014, São Paulo, SP, Brasil. 


\section{REFERÊNCIAS}

1 Lloyd-s Register-Fairplay. [Online] [Citado em: 2 de abril de 2013.] http://www.Ir.org/about_us/.

2 Chairman J. Weldability and Metallurgy of Welding of Steels. Welding in the World. Vol. 33. 1994.

3 Furuya, H. A New Proposal of HAZ Toughness Evaluation Method. Welding Journal, 2007.

4 TWI - Introductory Notes on Melallography of Welds in C-Mn Steels. UK, 1984.

5 Alé, R.M. Efeito da Adição de Elementos de Liga (Cu e Ni) nas Propriedades Mecânicas e Microestrutura da ZAC de Aços C-Mn Microligados ao Nb. s.l. : Tese de Doutorado em Engenharia Metalúrgica apresentada à COPPE/UFRJ, 1994.

6 A370, Norma ASTM. Test methods and definitions for mechanical testing of steel products. 2008.

7 Código ASME, Seção IX - Qualificação de Soldagem, 1980.

8 Meester B. The Weldability of modern structural TMCP steels. ISIJ v.37, n. 6, 1997.

9 Silva RF. Caracterização da zona termicamente afetada de aço produzido via resfriamento acelerado. Dissertação de Mestrado em Engenharia Metalúrgica apresentada à UFMG, 2010.

10 Tandberg S. Proc. Int. Conf. Welding in Engergy Related Projects. Toronto : s.n., 1983.

11 Kawano $\mathrm{H}$. Fatigue strength of thermo-mechanically controlled process steel and its weld joint, Japan: Proceedings of International Offshore and Polar Engineering Conference, 2002.

12 Kirkwood P. Niobium and Heat Affected Zone Mythology. Welding of High Strength Pipeline Steels. International Seminar,CBMM, Brasil. 2011.

13 Pisarski J, Kudoh HG. Exploratory Studies on the Fracture Toughness of Multipass Welds With Locally Embrittled Zones. The Welding Insitute. 1986.

* Contribuição técnica ao 69 Congresso Anual da ABM - Internacional e ao 14ํㅡㄹ ENEMET - Encontro Nacional de Estudantes de Engenharia Metalúrgica, de Materiais e de Minas, 21 a 25 de julho de 2014, São Paulo, SP, Brasil. 